\title{
Nursery nutrition in Liverpool: an exploration of practice and nutritional analysis of food provided
}

\author{
Mike Parker ${ }^{1, *}$, Ffion Lloyd-Williams², Gemma Weston' ${ }^{1}$, Julie Macklin ${ }^{1}$ and \\ Kate McFadden ${ }^{3}$ \\ ${ }^{1}$ HM Partnerships, Burlington House, Crosby Road North, Waterloo, Liverpool L22 OQB, UK: ${ }^{2}$ Division of \\ Public Health, University of Liverpool, Liverpool, UK: ${ }^{3}$ Children's Commissioning Team, Liverpool Primary Care \\ Trust, Liverpool, UK
}

Submitted 30 July 2010: Accepted 15 March 2011: First published online 20 May 2011

\begin{abstract}
Objective: To explore nutrition and food provision in pre-school nurseries in order to develop interventions to promote healthy eating in pre-school settings. Design: Quantitative data were gathered using questionnaires and professional menu analysis.

Setting: In the community, at pre-school nurseries.

Subjects: All 130 nurseries across Liverpool were a sent questionnaire (38\% response rate); thirty-four menus were returned for analysis (26\% response rate). Results: Only $21 \%$ of respondents stated they had adequate knowledge on nutrition for pre-school children. Sixty-one per cent of cooks reported having received only a 'little' advice on healthy eating and this was often not specific to under- $5 \mathrm{~s}$ nutrition. Fifty-seven per cent of nurseries did not regularly assess their menus for nutritional quality. The menu analysis revealed that all menus were deficient in energy, carbohydrate, Fe and Zn. Eighty-five per cent of nurseries had $\mathrm{Na} /$ salt levels which exceed guidelines.

Conclusions: Nurseries require support on healthy eating at policy, knowledge and training levels. This support should address concerns relating to both menu planning and ingredients used in food provision and meet current guidelines on food provision for the under- $5 \mathrm{~s}$.
\end{abstract}

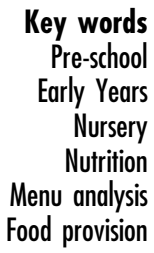

The period before a child starts primary school is one of the most critical times for his/her growth and development. Nutritious food provides the foundation required for the development of physiological systems and sets patterns of eating habits, good or bad, for life. The 2008 report by the Audit Commission (an independent watchdog in the UK, driving economy, efficiency and effectiveness in local public services to deliver better outcomes) examined the priorities given to children's health in the 0 to 5 years age group by local authorities and primary care trusts, and reviewed their approaches to achieving improvement in key areas such as obesity and infant mortality. The report states ${ }^{(1)}$ :

Evidence clearly demonstrates that improving early years' health contributes to better health outcomes in later life, with reduced levels of diabetes, coronary heart disease and hypertension, all of which have a significant impact on the National Health Service as well as wider society, children and their families.

To help children develop patterns of healthy eating from an early age, it is important that the food and eating patterns to which they are exposed - both at home and outside the home - are those which promote positive attitudes to good nutrition. The number of children attending full-day care in England has been rising steadily, doubling from 381600 in 2003 to 763505 in $2009^{(2)}$. A significant proportion of children attending nurseries are there from 07.00 to 19.00 hours and therefore receive the bulk of their food and nutrition from nursery ${ }^{(3)}$. Child-care settings therefore provide an important opportunity to contribute to a child's diet through the provision of healthy foods.

There is currently no statutory guidance for nurseries on the sourcing and provision of nutritious food for under- $5 \mathrm{~s}$ in their care. Ofsted (the Office for Standards in Education) states that 'food provision in early years settings should provide nutritious food and drink to meet the child's needs ${ }^{(4)}$ but does not attempt to define the term 'nutritious', instead leaving it open to interpretation. A preliminary review of current guidance for nurseries, undertaken by the School Food Trust (a charity that promotes the education and health of children and young people by improving the quality of food supplied and consumed in schools), states that although there is a large amount of guidance being produced, no single source is viewed as authoritative. While comprehensive guidelines 
have been produced by the Scottish Executive ${ }^{(5)}$, the Welsh Assembly ${ }^{(6)}$ and the Health Promotion Agency of Northern Ireland $^{(7)}$, there are currently none for England. The School Food Trust highlights the need for a 'more comprehensive, coherent food and nutrition guidance for nurseries that can be accessed easily and be delivered by all early years settings in England, ${ }^{(8)}$.

In 2008 a survey of children's centres and private nursery workers' experiences across England and Wales showed wide variation in the types and quality of food provided to children. Seventeen per cent felt that children were not given healthy food (i.e. at the nursery). In particular, it was felt that nurseries providing places for children from low-income families served less varied foods and foods were higher in sugar, saturated fat and salt and low in fibre, vitamins and minerals. Only $8 \%$ of nurseries responding to the survey ever served oil-rich fish and only $27 \%$ reported they regularly served water to their children as a drink ${ }^{(9)}$.

A survey of food provision in nurseries across Cheshire and Merseyside demonstrated that pre-school food policies on healthy eating were weak, with only three food policies of the fourteen provided making specific reference to the need to reduce fat, salt and sugar, and only one policy making reference to the long-term health implications of the childhood diet. They closely reflected the ambiguity in the current non-statutory national guidance by Ofsted ${ }^{(4)}$. In addition, training on healthy eating for nursery cooks was not common or considered a priority in the pre-school sector. Only $20 \%$ of pre-school catering managers or head cooks had received training on healthy eating in the last 12 months and there was a general lack of awareness on the need to take action to reduce excess saturated fat intakes in pre-school children ${ }^{(10)}$.

In summary, there is a growing body of evidence which indicates that food provided in pre-school settings is insufficiently nutritious based upon the nutritional requirements of children aged $<5$ years. This is primarily due to a lack of statutory guidance. In order to contribute and add to the existing evidence, the present study aimed to:

1. Identify current food provision across the children's nursery sector in Liverpool.

2. Explore current knowledge, attitudes and skills of staff in early years settings.

3. Carry out a nutritional analysis of nursery menus (3-week cycle for each nursery).

\section{Methods}

The study was carried out between September 2009 and July 2010.

\section{Questionnaire}

A questionnaire was designed to assess food policy, provision and current practices relating to nutrition in nurseries. The questionnaire was developed from an analysis of existing questionnaires including the 'Survey of Food Provision in Nurseries in Cheshire and Merseyside $^{,(10)}$ and in consultation with the project's expert reference panel (experts in young children's nutrition from academia, Liverpool Primary Care Trust, Liverpool children's services, Liverpool City Council and the voluntary sector).

The questionnaire collected data relating to: information about the nursery (e.g. nursery type, number of staff, number of children registered); food policy and purchasing practice; menu planning (including assessment of nutritional content); food ingredients; preparation and provision; catering or nutritional qualifications (e.g. City and Guilds, food hygiene, healthy eating for under- $5 \mathrm{~s}$ ); and children's eating habits. The knowledge and attitudes of staff towards the nutritional needs of pre-school children was also assessed by asking how strongly they agreed or disagreed with a number of statements; for example, 'Dietary habits have little impact on the health of pre-school children' and 'Dietary requirements are about the same for children aged 6 months -5 years'.

The questionnaire was posted with an explanatory letter to all 130 Liverpool nursery managers, including Sure Start children's centres identified by Liverpool Primary Care Trust. All nurseries were sent a reminder letter and another copy of the questionnaire two weeks following the initial distribution.

Following the reminder letter, the project researcher attempted to contact all nurseries by telephone to offer telephone or face-to-face support in completing and returning the questionnaire.

\section{Questionnaire analysis}

Questionnaire data were inputted into an Excel 2007 workbook (Microsoft Corporation, Redmond, WA, USA) for comparison and a descriptive analysis was undertaken. Advanced filtering was used to compare and contrast data, including nursery type and location (i.e. neighbourhood management area, NMA).

Statistically significant differences in availability of different food groups between groups of nurseries (e.g. according to area, type of nursery) were assessed using the $\chi^{2}$ test via the SPSS statistical software package version 18 (SPSS Inc., Chicago, IL, USA).

\section{Menu analysis}

Nurseries were supported in submitting full 3-week cycle menus and recipes for analysis. Although nurseries were encouraged to post back their menu cycles, in many cases the researcher visited the nurseries to collect the menu cycles and the full recipe information. Menus/recipes were analysed using a standardised computer package (Saffron Nutrition Analysis Software; Fretwell Downing Hospitality, Sheffield, UK) to investigate whether the food provided by nurseries in Liverpool met nutritional recommendations as 
detailed in the Caroline Walker Trust (CWT) guidelines ${ }^{(11)}$, which were used as a baseline to measure food provision.

The CWT guidelines stipulate that children in full-day care should receive:

(a) a morning snack;

(b) lunch (with dessert);

(c) an afternoon snack;

(d) tea (with dessert).

The CWT guidance also states that children up to the age of 2 years should be given whole milk as standard and that semi-skimmed milk can be introduced after this age.

The CWT guidance specifies the amount of twelve different nutrients children should obtain from their nursery food; these are listed in Table 1 . The process required a detailed level of information in order to provide a comprehensive analysis which accurately reflected the current nutritional status of the nursery menus offered.

The following process was used.

1. Analysis of each recipe to establish nutritional content.

2. Where no recipe or only part of a recipe was provided, an analysis of a menu cycle was carried out using the most appropriate recipes drawn from different sources including the Menu Matters database ${ }^{(12)}$, the CWT guidelines $^{(11)}$ and the Food Standards Agency (FSA) food portion sizes review ${ }^{(13)}$.

3. Where an ingredient description was ambiguous, the supplier's website was used to obtain ingredient weights and nutritional information.
4. Recipes were built into menu plans, analysed against the CWT nutrient-based standards and assessed from very good compliance (where minor adjustments would provide balanced menus) to poor compliance (where a complete restructure of recipes and menu cycles was needed).

5. Full menu data were split into component meals and analysed separately as follows: a snacks plan; a lunch plan (main meal); and a tea plan.

6. Reports were compiled based on analysis by: NMA (this enabled identification of any pockets of bad or conversely good practice and identify possible reasons for this); nursery type, i.e. private, children's centres and voluntary-run nurseries (this enabled examination of major differences between response rates from private and public nurseries and any nutritional differences via these categories); and nutrients (this enabled comparison of nutrient profiles in different NMA).

\section{Results}

\section{Response rate}

Questionnaire

A total of 120 telephone contacts were made out of a possible 130. In total, eighty-six telephone or face-to faceinterviews were conducted (seventy-one by telephone and fifteen face to face). The reasons for the interviews were: to collect questionnaires where they were not

Table 1 Nutrient-based standards for food prepared for 3- to 4-year-olds in child care ${ }^{(11)}$

\begin{tabular}{|c|c|c|c|c|c|c|}
\hline Nutrient (examples of sources) & Full-day care* & $\begin{array}{l}\text { Morning session: } \\
\text { snack and } \\
\text { lunch }\end{array}$ & $\begin{array}{l}\text { Afternoon } \\
\text { session: snack } \\
\text { and tea }\end{array}$ & $\begin{array}{l}\text { Snack } \\
\text { only }\end{array}$ & $\begin{array}{l}\text { Lunch } \\
\text { only }\end{array}$ & Tea only \\
\hline Energy (kJ) & 4338 & 2479 & 1859 & 620 & 1859 & 1239 \\
\hline Energy (kcal) & 1036 & 592 & 444 & 148 & 444 & 296 \\
\hline Fat (g) (oily fish, e.g. salmon, sardines) & $40 \cdot 3$ & $23 \cdot 0$ & $17 \cdot 3$ & $5 \cdot 7$ & $17 \cdot 3$ & $11 \cdot 6$ \\
\hline $\begin{array}{l}\text { Total carbohydrate (g) (bread, breakfast } \\
\text { cereals, pasta) }\end{array}$ & $138 \cdot 1$ & $78 \cdot 9$ & $59 \cdot 2$ & $19 \cdot 7$ & $59 \cdot 2$ & $39 \cdot 5$ \\
\hline $\begin{array}{l}\text { NMES }(\mathrm{g}) \text {, maximum (sweets, biscuits, } \\
\text { cakes, fruit juice) }\end{array}$ & $30 \cdot 3$ & $17 \cdot 3$ & $13 \cdot 0$ & $4 \cdot 3$ & $13 \cdot 0$ & $8 \cdot 7$ \\
\hline $\begin{array}{l}\text { Protein }(\mathrm{g}) \text {, minimum (milk, meat, fish, } \\
\text { cheese, pulses) }\end{array}$ & $11 \cdot 9$ & $6 \cdot 8$ & $5 \cdot 1$ & $1 \cdot 7$ & $5 \cdot 1$ & $3 \cdot 4$ \\
\hline $\begin{array}{l}\text { Fe }(\mathrm{mg}), \text { minimum (meat, oily fish, } \\
\text { cereals, vegetables) }\end{array}$ & $5 \cdot 3$ & $3 \cdot 0$ & $2 \cdot 3$ & $0 \cdot 7$ & $2 \cdot 3$ & $1 \cdot 6$ \\
\hline $\begin{array}{l}\text { Zn (mg), minimum (meat, eggs, milk, } \\
\text { wholegrain cereals) }\end{array}$ & $4 \cdot 6$ & $2 \cdot 6$ & $2 \cdot 0$ & 0.6 & $2 \cdot 0$ & $1 \cdot 4$ \\
\hline $\begin{array}{l}\text { Ca }(\mathrm{mg}), \text { minimum (milk, yoghurt, } \\
\text { cheese, pulses) }\end{array}$ & 280 & 160 & 120 & 40 & 120 & 80 \\
\hline $\begin{array}{l}\text { Vitamin } A(\mu \mathrm{g}) \text {, minimum (fortified } \\
\text { margarine, cheese) }\end{array}$ & 315 & 180 & 135 & 45 & 135 & 90 \\
\hline $\begin{array}{l}\text { Vitamin } C(\mathrm{mg}) \text {, minimum (citrus fruits, } \\
\text { red/green peppers, potatoes) }\end{array}$ & 21 & 12 & 9 & 3 & 9 & 6 \\
\hline $\begin{array}{l}\mathrm{Na}(\mathrm{mg}) \text {, maximum (bacon, ham, salted } \\
\text { snacks) }\end{array}$ & 700 & 400 & 300 & 100 & 300 & 200 \\
\hline $\begin{array}{l}\text { Salt (g), maximum (bacon, ham, salted } \\
\text { snacks) }\end{array}$ & $1 \cdot 75$ & $1 \cdot 0$ & $0 \cdot 75$ & 0.25 & $0 \cdot 75$ & 0.5 \\
\hline
\end{tabular}

NMES, non-milk extrinsic sugars.

${ }^{*}$ Full-day care includes a morning snack, lunch, afternoon snack and tea. It does not include breakfast. 
Table 2 Level of information supplied for menu analysis by responding nurseries ( $n$ 20), Liverpool, UK, September 2009 to July 2010

\begin{tabular}{lcccc}
\hline Information supplied & Full cycle* & Lunch only & Tea only & Best case \\
\hline Full recipes and menu cycles & 2 & 1 & & Worst case \\
Part recipes and menu cycles & 9 & 6 & 1 & 34 \\
Menu only (no recipes) & 9 & 6 & 1 & 13 \\
Total & 20 & 13 & & \\
\hline
\end{tabular}

${ }^{\star}$ Full cycle refers to all the food provided during the course of the day at nursery, i.e. lunch, tea and snacks.

returned by post; to complete those questionnaires that were returned incomplete; and to support nurseries with the submission of menu cycle and full recipe information. This resulted in forty-nine (38\%) questionnaires being returned.

\section{Menu analysis}

Thirty-four nurseries provided recipes/menu plans. Seven hundred and eighty-three recipes were inputted and analysed with Saffron Nutrition Analysis Software. One hundred and two menu plans were compiled and analysed against the relevant CWT nutrient-based standards: full day, $n$ 20; lunch (main meal), $n$ 34; tea, $n$ 21; and snack, $n 27$.

Only $35 \%$ of nurseries that responded to menu analysis provided full cycles (i.e. lunch, snacks and tea; see Table 2). Thirty-five per cent provided (a), (b), (c) and (d) above; 55\% provided (a), (b) and (d) - no afternoon snack; and $10 \%$ provided only (b) and (d) - no snacks.

Response rate by nursery type

Of the forty-nine (38\%) questionnaires returned, $61 \%$ of responses came from private providers, 33\% from Sure Start (public sector), $4 \%$ voluntary and $2 \%$ from other providers (a hospital-based nursery).

There was a $26 \%$ response rate for the returned menu (part menu). As with the questionnaire, response rates were highest from the private sector (53\%) with $44 \%$ from Sure Start (public sector) and 3\% from the voluntary sector.

\section{Food and drinks provision}

Whole milk was served by $82 \%$ of nurseries, with $43 \%$ offering semi-skimmed milk to the older children. One nursery offered skimmed milk, which is not recommended in professional guidelines.

Ninety-six per cent of nurseries offered tap water constantly during the day. Twenty-two per cent offered diluted fruit juice to their children, $4 \%$ diluted squash and $4 \%$ diluted sugar-free squash (generally at meal and snack times).

\section{Fats}

Forty-six per cent of nurseries reported using a vegetable oil for cooking and a polyunsaturated margarine for general use. However, half of responding nurseries did not state the name of any fat they used for cooking or as a spread.

Oily fish

Oily fish provision was significantly lower than specified in the CWT guidelines. Nearly $40 \%$ of nurseries supplied oily fish less than once weekly, $20 \%$ reported that they supply it once or twice weekly.

\section{Processed meat}

Two nurseries reported serving processed meat (e.g. sausages, canned meat, fish fingers) five or more times weekly. All others stated that they served processed meat no more than once or twice weekly. Pies, pastries and pasties were available in most cases less than once weekly.

\section{Snacks}

Eighty-six per cent of nurseries provided chopped fruit daily to the children. Sixty-five per cent provided chopped vegetables as a snack. Other snacks listed by nurseries included cakes and biscuits, toast, yoghurts, crisps, nuts, cereal bars and sandwiches.

\section{Early years catering facilities}

Eighty per cent of nurseries reported having fully equipped kitchens, suitable for preparing and producing meals. A further $18 \%$ had minimal facilities suitable only for reheating meals or preparing snacks. Twenty per cent of nurseries had a specific dining room facility for the consumption of food, while $69 \%$ served food in the main nursery room. Seventy per cent of responding nurseries prepared food on site with the remaining 30\% using an external food provider. There was a considerable difference between public and private providers however, with only $38 \%$ of public providers preparing their own food compared with $90 \%$ in the private sector.

\section{Spend per child per main meal}

Four per cent of nurseries reported spending less than $£ 0.50(0.57 €)$ per child per main meal. Twenty per cent spent between $£ 0.50$ and $£ 0.99(0.57-1 \cdot 10 €)$, with the average spend per child per main meal being between $£ 1 \cdot 00$ and $£ 2 \cdot 00(1 \cdot 10-2 \cdot 30 € ; 27 \%)$. Thirty-seven per cent of respondents did not know how much they spent on food per child per main meal. 
Early years food policy

Of the forty-nine nurseries responding to the questionnaire, $77 \%$ reported that they had a food policy. While there is no statutory requirement on early years settings to have a policy on food, best practice and guidance $^{(5,6,7,11)}$ would support the expectation that all early years settings have a policy that supports the provision of nutritious food and drink.

\section{Staff knowledge, attitudes and skills}

In $35 \%$ of nurseries the catering manager/cook was solely responsible for menu planning. In a further $33 \%$ of nurseries menu planning was the sole responsibility of the nursery manager. Thirty-two per cent reported joint (cook and manager) responsibility.

Approximately $43 \%$ of nurseries reported that their menus were always assessed for nutritional content. However, only two nurseries reported having their menus assessed by a nutritionist. The majority reported the assessment being carried out by the nursery manager/ cook only (i.e. self-assessment). Thirty-seven per cent reported that they had never been assessed.

Forty-three per cent of menu planners stated only food hygiene as their main qualification for food provision in the nursery setting, $8 \%$ of those responsible for menu planning did not state any catering or nutrition qualifications.

Fourteen per cent of respondents had received no specific healthy eating advice (i.e. information about the nutritional needs of under-5s) and a further $61 \%$ had only ever received 'a little' advice. Those who reported they had received advice (25\%) did not state the source.
Only $61 \%$ of respondents thought that their knowledge of nutrition for pre-school children was adequate.

Fifty-nine per cent of respondents reported that they were aware of nutritional guidance for under- $5 \mathrm{~s}$. However, of these, $38 \%$ did not state the guidance (despite being asked). Of those that stated guidance, the majority $(33 \%)$ stated FSA guidance ${ }^{(14)}$; others listed their source as the School Food Trust ${ }^{(15)}$, the National Institute for Health and Clinical Excellence ${ }^{(16)}$, Early Years Foundation Stage ${ }^{(17)}$, the 5-a-day guide from the National Health Service $^{(18)}$ and the Pre-school Learning Alliance ${ }^{(19)}$. Only one nursery named the CWT guidance, 'Eating well for under-5s in child care ${ }^{,(11)}$.

\section{Menu analysis}

Twenty nurseries provided full menu cycles (i.e. lunch, snacks and tea). Figure 1 summarises the compliance of the twenty responding nurseries with the CWT nutrientbased standards for full-day care.

There were major differences between the most and least compliant nurseries within the sample. Results ranged from very good compliance $(4.5 \%$ variance to target), where minor adjustments were required, to poor compliance (33\% variance to target), where a complete restructure of recipes and menu cycles was needed.

\section{Lunch only}

While lunch was the meal most compliant with the nutrientbased standards within the menu cycle, on average, lunch menus were deficient in energy, carbohydrate, Fe and $\mathrm{Zn}$ and had excess $\mathrm{Na}$ /salt levels (Fig. 2).

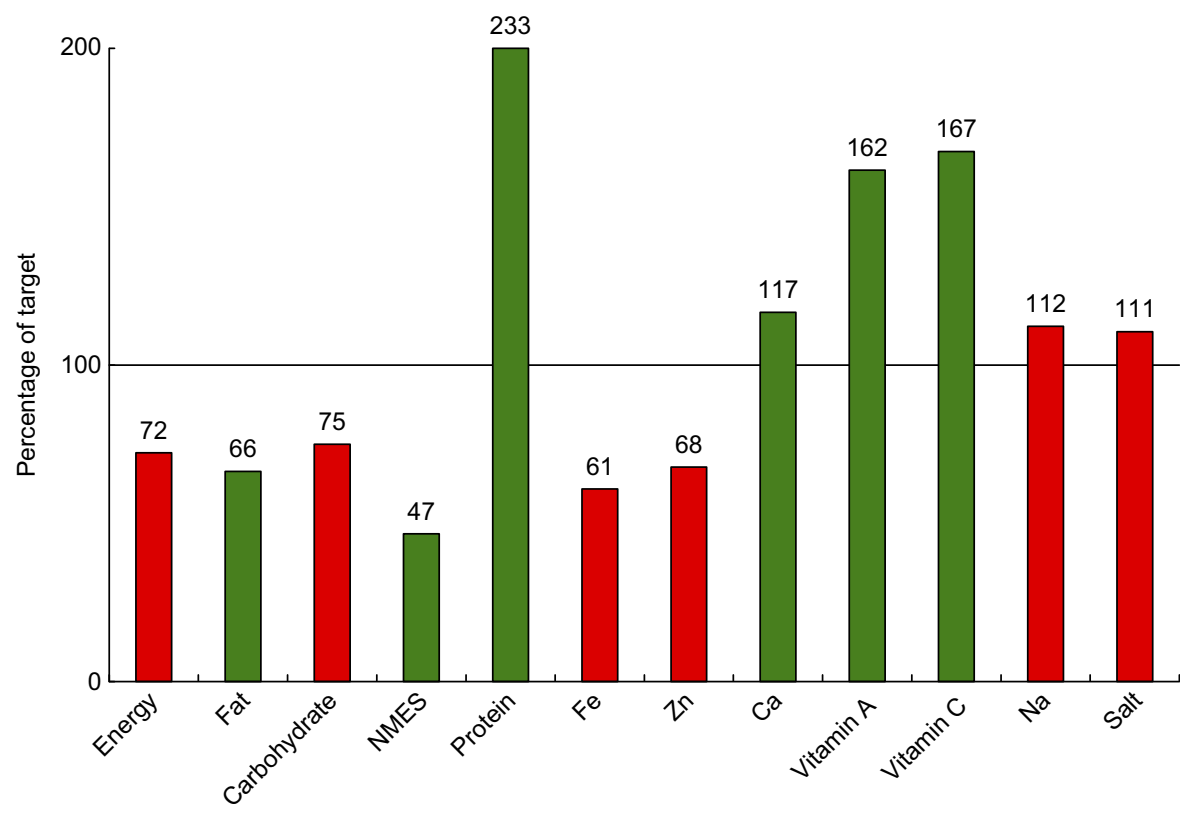

Fig. 1 (Colour online) The compliance of full cycle menus $(\square$, level of the nutrient in the menu is compliant; $\square$, level of the nutrient in the menu is not compliant, i.e. does not reach a minimum target or exceeds a maximum level) with the Caroline Walker Trust nutrientbased standards for responding nurseries ( $n$ 20), Liverpool, UK, September 2009 to July 2010 (NMES, non-milk extrinsic sugars; full cycle refers to all the food provided during the course of the day at nursery, i.e. lunch, tea and snacks) 


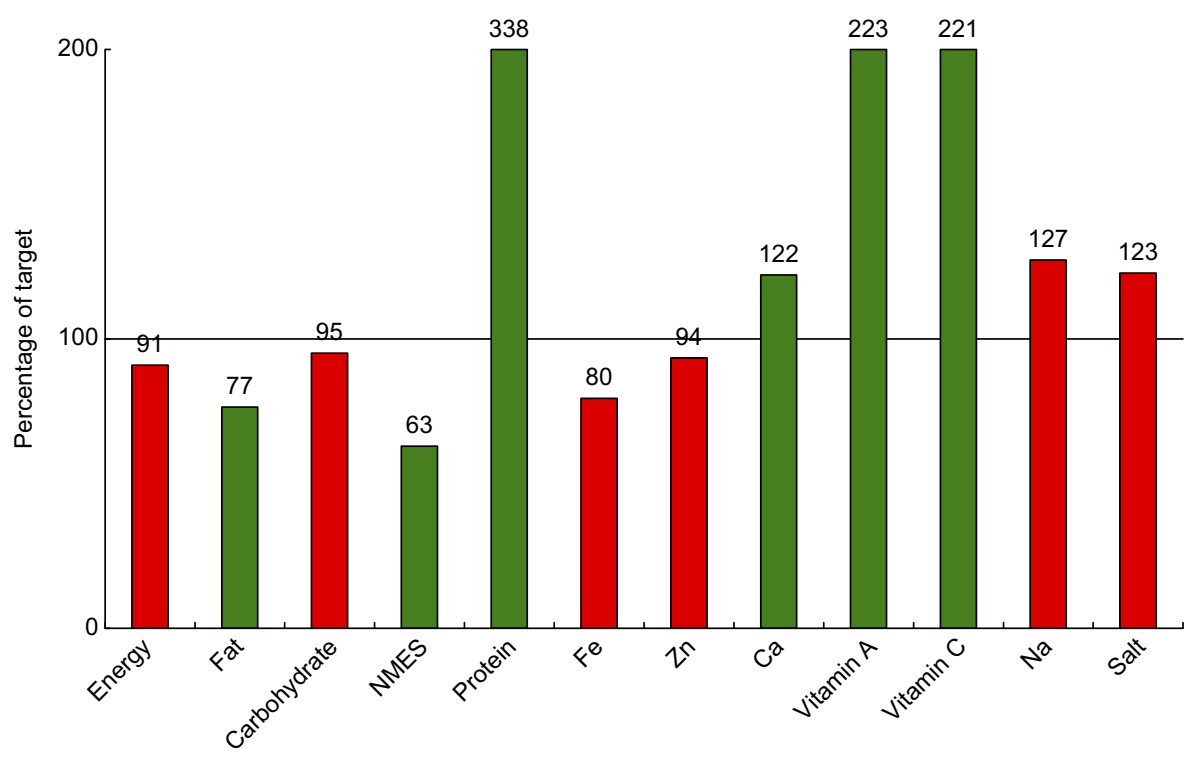

Fig. 2 (Colour online) The compliance of lunch menus ( $\square$, level of the nutrient in the menu is compliant; $\square$, level of the nutrient in the menu is not compliant, i.e. does not reach a minimum target or exceeds a maximum level) with the Caroline Walker Trust nutrientbased standards for responding nurseries ( $n$ 20), Liverpool, UK, September 2009 to July 2010 (NMES, non-milk extrinsic sugars)

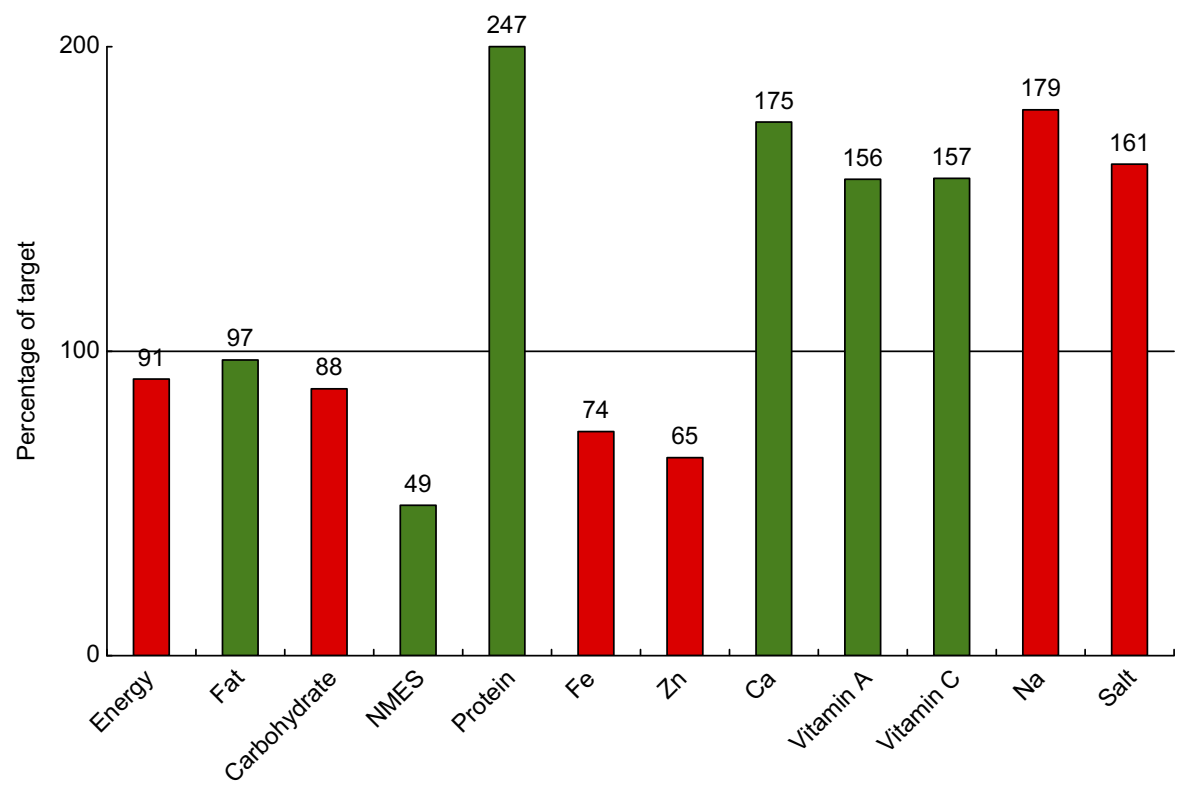

Fig. 3 (Colour online) The compliance of tea menus ( $\square$, level of the nutrient in the menu is compliant; $\square$, level of the nutrient in the menu is not compliant, i.e. does not reach a minimum target or exceeds a maximum level) with the Caroline Walker Trust nutrientbased standards for responding nurseries ( $n$ 20), Liverpool, UK, September 2009 to July 2010 (NMES, non-milk extrinsic sugars)

\section{Tea only}

On average, tea menus were deficient in energy, carbohydrate, Fe and $\mathrm{Zn}$ and had very high $\mathrm{Na}$ /salt levels significantly exceeding recommended levels (Fig. 3).

\section{Snacks only}

On average, snack menus were significantly deficient in energy, carbohydrate, Fe and Zn (Fig. 4).
In summary, none of the nurseries within the sample complied fully with the CWT nutrient-based guidelines for any of the meals or the full cycle. All cycles were deficient in energy, carbohydrate, Fe and $\mathrm{Zn}$. Full menus, lunches and teas all contained too much $\mathrm{Na}$ /salt. Snacks were most deficient in energy, carbohydrate, Fe and $\mathrm{Zn}$. Teas had the highest excess of salt. 


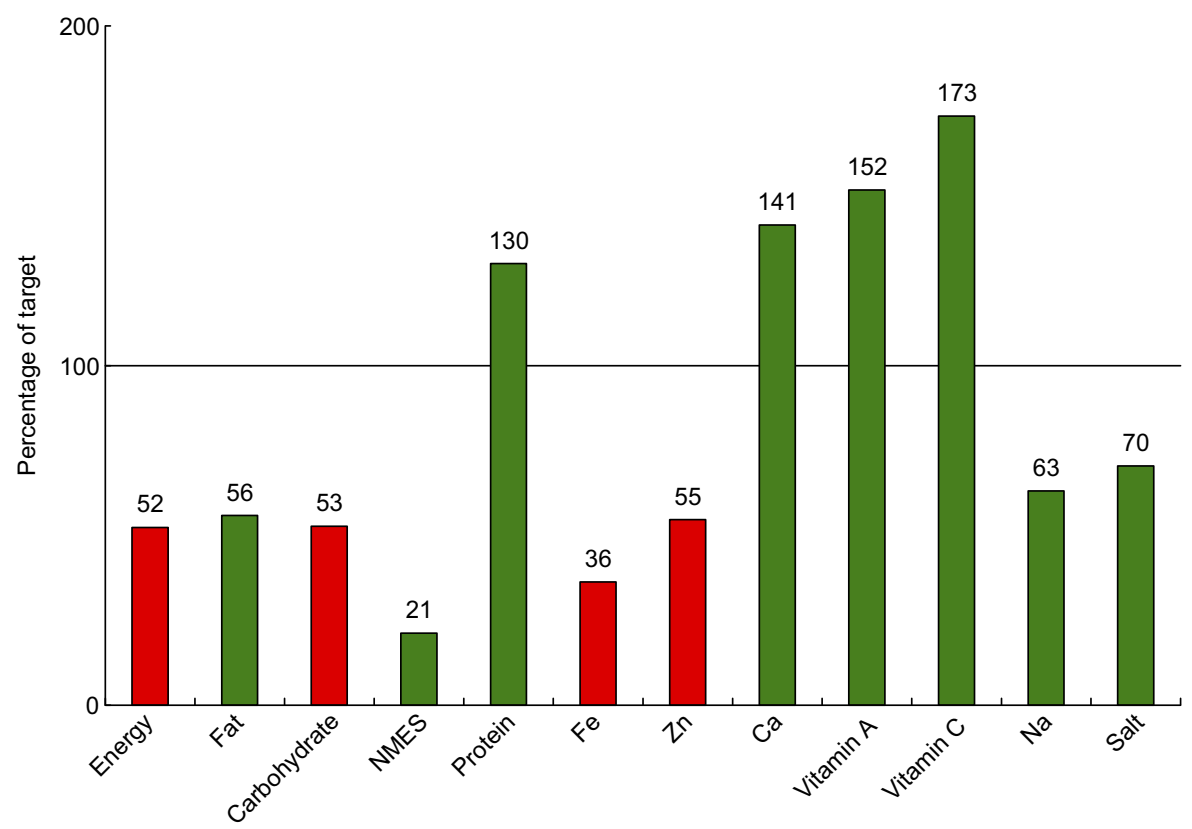

Fig. 4 (Colour online) The compliance of snack menus ( $\square$, level of the nutrient in the menu is compliant; $\square$, level of the nutrient in the menu is not compliant, i.e. does not reach a minimum target or exceeds a maximum level) with the Caroline Walker Trust nutrientbased standards for responding nurseries ( $n$ 20), Liverpool, UK, September 2009 to July 2010 (NMES, non-milk extrinsic sugars)

\section{Analysis by neighbourbood management area}

Further comparative analysis was carried out to determine whether there were any particular trends in nursery food provided in different NMA. Lunches were chosen as the common denominator to include data from all nurseries. Non-compliant nutrients were energy, carbohydrate, Fe, $\mathrm{Zn}$ and $\mathrm{Na}$ /salt. All others were compliant. Every NMA was too low for energy, $\mathrm{Zn}$ and Fe. Every NMA was too high for $\mathrm{Na} /$ salt. Carbohydrate and $\mathrm{Zn}$ levels were compliant in only two NMA.

\section{Analysis by nursery type}

Comparative analysis was carried out to determine whether there were any particular trends in nursery food provided by different nursery types. There was very little variation in menus from private and public (Sure Start) sectors in relation to conformity to the CWT nutrientbased standards. It was the individual nursery, not the type, which determined the nutritional quality of the food provided. There were examples of good and poor practice within both sectors. Good examples included using no or limited processed foods, cooking food from scratch without adding salt or using ingredients high in salt (i.e. gravy granules), and using healthier cooking methods including baking and grilling. Poor examples included having an over-reliance on the use of processed foods and using products high in salt (i.e. gravy granules).

Analysis by nutrient based upon full menu cycle Total energy provision across all nurseries was below UK recommendations ${ }^{(4,11)}$. The average percentage of energy provided by fat in the sample group was slightly below government recommendations $(31 \% \quad v$. recommended $36 \%)$. None of the nurseries met the target guideline for total carbohydrate. Eighty-five per cent of the nurseries exceed the maximum guideline for $\mathrm{Na}$, with one nursery providing $143 \%$ of the recommended maximum, and only three of the nurseries came under the recommended maximum amount. None of the nurseries met the target guideline for Fe or $\mathrm{Zn}$. Forty per cent of the nurseries did not meet the target guideline for $\mathrm{Ca}$, with one nursery reaching only $44 \%$ of the target. The sample exceeded the minimum requirements for protein. All nurseries which provided full menu cycles fell within the maximum guideline for non-milk extrinsic sugars.

\section{Discussion and conclusions}

The findings reported here are largely consistent with other studies conducted in the last few years in the UK at national ${ }^{(6,20)}$, regional ${ }^{(21-23)}$ and local levels ${ }^{(10,24)}$. This includes: food policies containing information about healthy eating relating to the nutritional needs of under- $5 \mathrm{~s}$ are rare; cooks lack training in nutrition and food requirements of under- $5 \mathrm{~s}$; the use of processed foods such as sausages, canned meat, bottled/packet sauces and gravy mixes is leading to high salt levels which are unacceptable for under- $5 \mathrm{~s}$; and the provision of foods with essential fatty acids such as oily fish is below recommended levels.

A qualitative survey ${ }^{(25)}$, carried out in Liverpool within the same time frame as the present study, reported issues 
relating to the need for clear national statutory guidance, support for nurseries to develop appropriate healthy eating policies, and training for nursery staff especially managers and cooks.

We found that not all nurseries had a food policy and a healthy eating policy was rare. The menu analysis revealed that statements made in food policies did not reflect the nutritional content of recipes provided. For example, some food policies stated that menus were low in fat and salt, whereas the food analysis revealed menus to be high in fat and salt. There is a need to evaluate food policies in more detail and provide support to nurseries in both the production and implementation of a healthy eating policy.

The average cost of a main meal per child in Liverpool nurseries was reported as $£ 1 \cdot 00-2 \cdot 00$. This figure compares favourably with the average cost in secondary schools of $£ 1 \cdot 60^{(26)}$. Nurseries appear to be spending sufficiently on food within their setting. However, when considering the menu analysis, we would suggest an opportunity to offer advice on ensuring optimum use of that spend to provide a nutritious meal in line with CWT guidance.

Less than half of respondents reported having their menus assessed for nutritional content and only $4 \%$ reported that an assessment had been carried out by a qualified nutritionist. This is considerably less than comparable studies elsewhere in the Merseyside region, North West England ${ }^{(10,24)}$. Mwatsama ${ }^{(10)}$ reported $38 \%$ of menus being assessed for nutritional content in 2006, and Sefton Council $^{(24)}$ reported $42 \%$ of menus being assessed for nutritional content in 2007.

Respondents demonstrated an understanding of the importance of the nutritional quality of food served to children in relation to their health, but only one in four nurseries strongly agreed that they have adequate knowledge in this area. Our responses are broadly in line with those from similar studies in this area ${ }^{(9,10,20-25)}$. There is a key requirement to support nurseries through targeted, specific training focusing on under- 5 s nutrition. Due to the importance of the food environment and the interaction of other nursery staff during meal times, this training should also be offered to early years practitioners and nursery managers.

The menu analysis revealed that the nurseries were actually serving less than the recommended energy levels for this age group. Based on this finding there is a need to work with nurseries to ensure appropriate portion size at meal and snack times. A breakdown of energy sources revealed the nurseries broadly met guidance for carbohydrate, fats and protein. In general, nurseries met or exceeded vitamin requirements primarily due to the amount of fruit and vegetables served at meal and snack times. However, some nurseries did not use any vegetables within dishes like bolognaise (the sauce was made with just mince and gravy) and they were far more willing to serve fruit as snacks rather than vegetables.
Of greatest concern from the menu analysis were the levels of $\mathrm{Na}$ /salt served to these under- $5 \mathrm{~s}$, with the majority of nurseries serving excessive levels. The majority of salt came from ready-made stock and stock cubes and thickeners used in meal production, rather than adding salt in the cooking process. Many nurseries were also still serving high levels of processed meats which again are high in salt. There were also deficiencies in $\mathrm{Fe}$ and $\mathrm{Zn}$ across the menus, both vital in the development of under-5s. These issues could be included during training sessions to ensure these nutrients are adjusted to acceptable levels as indicated in guidance.

The study does have its limitations. The response rate was low and therefore the findings may not be a true reflection of food provision across the Liverpool early years setting. Responders may have been demonstrating best practice (e.g. low salt and low saturated fat) in nursery food provision across Liverpool. Over the past 10 years there has been increased awareness of correct messages for healthy eating, such as 5-a-day, impact of processed foods, salts and obesity. Therefore questionnaire respondents may have been providing answers they thought were right as opposed to reporting actual practice.

In conclusion, the present study demonstrates that nurseries wish to ensure the food they provide is appropriate and nutritious for under- $5 \mathrm{~s}$ in their care. However, many staff do not have sufficient knowledge, due to a lack of training about the nutritional requirements of under- $5 \mathrm{~s}$, and are unaware of or unable to obtain authoritative guidance concerning food provision.

\section{Recommendations}

In order to address these issues, the following need to be implemented: a nationally accredited training package for pre-school caterers and staff; development of a standard healthy eating policy for all early years settings; development of national statutory nutritional guidance support for under- $5 \mathrm{~s}$ aimed at parents and nursery staff; and professional support for all early years settings in menu planning.

\section{Acknowledgements}

The work took place at HM Partnerships (Liverpool, UK), a public health consultancy established as a Community Interest Company. As a social enterprise, its profits are re-invested into the prevention of CVD through the charity, Heart of Mersey. The study was funded by Liverpool First for Health. All authors have no commercial, personal, political or academic conflicts of interest. F.L.-W. and K.M. conceived and managed the research project together with the project steering group. G.W. and M.P. carried out the fieldwork and analysis. F.L.-W. wrote and edited the article, 
with contributions from K.M., G.W., J.M. and M.P. All authors read and revised all versions of the manuscript. The authors would like to thank Liverpool First for Health for providing the funding to carry out the research; all nursery staff who gave their time to take part in the study; and the project steering group for their expertise in guiding project development and delivery. They also thank Nicky Dexter and Andrea Kelly from Menu Matters for providing professional nutritional analysis of menus.

\section{References}

1. Audit Commission (2008) Giving Children a Healthy Start. London: Audit Commission; available at http://www.auditcommission.gov.uk/SiteCollectionDocuments/Downloads/ givingchildrenahealthystart.pdf2

2. Office for Standards in Education (2010) Registered Childcare Providers and Places in England. London: Ofsted; available at http://www.ofsted.gov.uk/Ofsted-home/ Publications-and-research/Browse-all-by/Documents-bytype/Statistics/Childcare-and-early-years/(year)/2010

3. National Day Nursery Association (2007) Childcare - A Sustainable Mixed Economy, Policy Paper. London: National Day Nursery Association.

4. Department for Education and Skills (2005) Healthy School Lunches for Pupils in Nursery Schools/Units. Guidance for School Caterers on Implementing National Nutrition Standards. Nottingham: DfES Publications; available at http://media.education.gov.uk/assets/files/pdf/ $\mathrm{t} /$ the $\% 20$ complete\%20school\%20caterers\%20guidelines.pdf

5. Scottish Executive (2006) Nutritional Guidance for Early Years: Food Choices for Children Aged 1-5 Years in Early Education and Childcare Settings. Edinburgh: Scottish Executive; available at http://www.scotland.gov.uk/ Resource/Doc/89729/0021563.pdf

6. Welsh Assembly Government (2009) Food and Health Guidelines for Early Years and Childcare Settings. Cardiff: Welsh Assembly Government; available at http:// wales.gov.uk/docs/phhs/publications/foodandhealth/ 090414guidelinesen.pdf

7. Health Promotion Agency for Northern Ireland (2005) Nutrition Matters for the Early Years: Guidance for Feeding the Under Fives in Childcare. Belfast: HPAfNI; available at http://www.hpani.org/Resources/nutrition/ pdfs/nutmatters2006.pdf

8. Sharp L, Mucavele P \& Nelson M (2010) Preliminary Review of Early Years Food, Nutrition and Healthy Eating Guidance in England: A Summary. London: School Food Trust.

9. Organix \& Soil Association (2008) Georgie Porgie Pudding and Pie: Exposing the Truth about Nursery Food. Bristol: Organix \& Soil Association; available at http://www.soilassociation.org/LinkClick.aspx?fileticket $=$ P7\%2F0qfiUPe $4 \% 3$ D\&tabid $=388$

10. Heart of Mersey (2006) Nursery Food Provision, Policy and Practice across Cheshire and Merseyside. Report of a Survey of Food Provision in Nurseries across Cheshire and Merseyside to Support the Big Noise Social Marketing Project. Liverpool: Heart of Mersey; available at http:// www.heartofmersey.org.uk/cms_useruploads/files/hom_ 1162897023_hom_nursery_food_provision,_po.pdf

11. Crawley $\mathrm{H}$ (2006) Eating Well for Under-5s in Child Care: Practical Nutritional Guidelines, 2nd ed. St Austell:
Caroline Walter Trust; available at http://www.cwt.org.uk/ pdfs/Under5s.pdf

12. Menu Matters (2010) Database of recipe nutritional values. http://www.menumatters.co.uk/ (accessed April 2010).

13. Church S (2008) Trends in Portion Sizes in the UK: A Preliminary Review of Published Information. London: Food Standards Agency; available at http://www.food. gov.uk/multimedia/pdfs/reviewportions.pdf

14. Office for Standards in Education, Department for Education and Skills \& Food Standards Agency (2004) Starting Early: Food and Nutrition Education of Young Children. Manchester: Ofsted, available at http://www.food.gov.uk/ multimedia/pdfs/ofstedearly.pdf

15. Department for Children, Schools and Families \& School Food Trust (2010) Guidance for Food and Drink Provision in Early Years Settings (March 2010). London: DCSF; available at http://www.schoolfoodtrust.org.uk/ download/documents/pdf/early_years_food_and_nutrition_ guidance.pdf

16. National Institute for Health and Clinical Excellence (2008) Improving the Nutrition of Pregnant and Breastfeeding Mothers and Children in Low-income Housebolds. NICE Public Health Guidance no. 11. London: NICE; available at http://www.nice.org.uk/nicemedia/live/11943/40097/ 40097.pdf

17. Department for Children, Schools and Families (2010) Early Years Foundation Stage Framework. London: DCSF; available at http://nationalstrategies.standards.dcsf.gov.uk/ search/earlyyears/results/nav: 46528

18. National Health Service (2007) 5 a day: Just eat more (fruit and veg). London: NHS.

19. Pre-school Learning Alliance (2009) Feeding Young Imaginations. Nutritional Guidance for the Under Fives. London: Pre-school Learning Alliance.

20. Local Authorities Government Co-ordinators of Regulatory Services (2010) Councils Working with Nurseries to Improve Nutritional Standards. London: LACORS; available at http://www.lacors.gov.uk/lacors/upload/24525.doc

21. East Sussex County Council (2007) Nipper's Nutrition: A Study into the Nutritional Quality of Meals Provided by Local Nurseries for Children Less Than Five Years Old. Lewes: East Sussex County Council Trading Standards Service; available at http://www.eastsussex.gov.uk/NR/ rdonlyres/C5871E40-570B-41EC-9FCA-6D022FDB5F20/0/ nippersnutrition.pdf

22. Shaw J \& Mindlin M (2006) Are Children in Childcare Given Snacks which Comply with National Guidelines? Teddington: Richmond and Twickenham PCT, St Georges University of London.

23. Moore H, Nelson P, Marshall J et al. (2005) Laying foundations for health: food provision for under $5 \mathrm{~s}$ in day care. Appetite 44, 207-213.

24. Sefton Council (2007) Food and Nutrition in Nursery Settings: Project Report 2006-2007. Southport: Sefton Council, Environmental Protection; available at http:// www.sefton.gov.uk/pdf/epd_nursery\%20analysis.pdf

25. Lloyd-Williams F, Bristow K, Capewell S et al. (2010) Young Children's food in Liverpool day-care settings: reducing inequalities in pre-school nutrition policy and practice. Public Health Nutr (Epublication ahead of print version).

26. Association for Public Service (2008) School Meals Trend Analysis. Excellence Briefing 08/02. Manchester: Association for Public Service Excellence; available at http:// www.apse.org.uk/briefings/08/08-02\%20School\%20meal $\% 20$ trend\%20analysis.pdf 